\title{
A COMPETÊNCIA REGULAMENTAR DA ANEEL: LIMITES DE ATUAÇÃO SOB A ÓTICA DO CASO DA RESOLUÇÃO 500/2012
}

\section{REGULATORY COMPETENCE OF ANEEL: LIMITS OF ACTING UNDER PERSPECTIVE OF THE CASE FROM RESOLUTION 500/2012}

\author{
Larissa Urruth pereira 1 \\ Luciana Oliveira De Campos 2
}

\section{RESUMO}

Desde a chamada reforma do Estado, em meados dos anos 90, o Brasil adota o modelo regulador, formado por autarquias em regime especial, que normatizam e fiscalizam, de forma técnica, mercados 'desestatizados'. A competência normativa dessas agências é alvo de diversos questionamentos. Neste trabalho, procurou-se, com base em estudo de caso que tem como objeto a Resolução n. 500/2012 da ANEEL, a qual estabelece os procedimentos para reembolso do custo de combustíveis de empreendimento que utilize carvão mineral nacional, analisar as controvérsias e os limites dessa competência regulamentar, que é pautada por conceitos indeterminados.

Palavras-chave: Agências reguladoras, Competência regulamentar, Audiência pública

\begin{abstract}
Since the reform of the state, in the mid-90s, Brazil has adopted a regulatory model, formed by authorities in special regime that regulate and supervise, in a technical way, "privatized" markets. The legislative power of these agencies is the subject of several questions. In this paper, the objective was, based on the case study which has as an object the Resolution n. 500 /2012 of ANEEL that establishes the procedures to reimbursement enterprise fuels that use national mineral coal, to analyze disputes and the limits of this regulatory power, which is marked by indeterminate concepts.
\end{abstract}

Keywords: Regulatory agencies, Regulatory competence, Public hearing

\footnotetext{
${ }^{1}$ Mestranda em Ciências Criminais e Especialista em Ciências Penais pela Pontifícia Universidade Católica do Rio Grande do Sul - Rio Grande do Sul - RS, Brasil. E-mail: indexlaw.ojs@hotmail.com

2

Mestranda em Direito e Sociedade pelo Centro Universitário UniLasalle, Rio Grande do Sul. RS - Braisl.

E-mail: indexlaw.ojs@hotmail.com
} 


\section{INTRODUÇÃO}

Desde meados da década de 90, alguns serviços públicos e também atividades econômicas importantes para o desenvolvimento social e econômico do País são regulados por agências constituídas na forma de autarquia especial, detentoras de corpo técnico especializado e autonomia reforçada para o exercício de suas funções que, em regra, compreendem desde a emissão de atos administrativos normativos até a fiscalização das atividades dos entes regulados ${ }^{1}$. Desde a criação das primeiras agências regulamentadoras brasileiras a questão da competência regulamentar é motivo de discussão. A adoção do modelo regulador, que exsurge em meio à chamada reforma do Estado, tem como objetivo assegurar maior estabilidade às atividades econômicas, elevar o grau de confiabilidade do mercado e, com isso atrair investidores para os setores chave da economia, bem como para área de prestação de serviço públicos essenciais, que deveriam ser prestados de forma mais eficiente e universal (AGUILLAR, 1999, p. 233-234).

Para regular o serviço público de energia elétrica, a ANEEL - Agência Nacional de Energia Elétrica, autarquia de regime especial, é criada pela Lei $n^{\circ} 9.427$, de 26 de dezembro de 1996, constituída por meio do Decreto $n^{\circ} 2.335$, de 06 de outubro de $1997^{2}$, sendo a primeira entidade desta natureza criada no Brasil, vinculada ao Ministério de Minas e Energia $^{3}$. Constituída para regular um setor absolutamente complexo e relevante, tanto do ponto de vista social, quanto econômico, tem suas competências definidas por lei, compreendendo desde a regulação propriamente dita até a fiscalização dos agentes regulados, alcançando diretamente empresas geradoras de energia elétrica, distribuidoras e usuários.

Trata-se de entidade dotada de importante grau de autonomia em relação ao Poder Executivo e possuidora de corpo técnico especializado, isso para que seu agir seja imparcial, técnico e especializado, devendo observar as competências, limites e diretrizes estabelecidas em lei, bem como nas políticas públicas voltadas ao setor. Dentre as diretrizes a serem

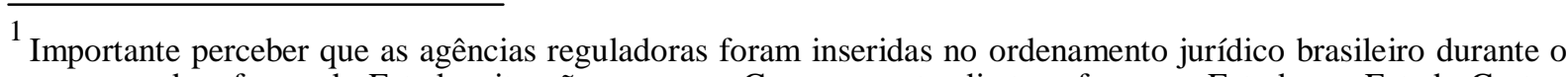
processo de reforma do Estado, situação em que o Governo pretendia transformar o Estado em Estado Gestor. (ARAGÃO, 2013; CARDOSO, 2010).

2 Egon Bockmann Moreira destaca que as autarquias são criadas por lei, mas instituídas por meio de Decreto do Poder Executivo, cuja competência é indelegável. O que significa que a lei apenas autoriza a existência da autarquia, a qual só existirá faticamente após a análise discricionária do Executivo, que entendendo pela conveniência e oportunidade de descentralizar a atividade constitui a autarquia por Decreto. (MOREIRA, 2006, p. 175).

3 Alexandre Santos de Aragão aponta que antes implementação das agências reguladoras no Brasil, já existiam instituições reguladoras, como o Banco Central, Comissão de Valores Imobiliários, Conselho Monetário
} 
Nacional, Instituto do Álcool e do Açúcar e Instituto Brasileiro do Café, com a diferença de que estas não possuíam independência (autonomia reforçada) em relação ao Poder Executivo. (ARAGÃO, 2013, p. 272).

observadas no exercício de suas competências estão: a universalização do serviço, as políticas públicas voltadas para o setor, a adoção da solução mais vantajosa para o usuário, a adequada remuneração das geradoras e distribuidoras e a manutenção do equilíbrio econômico financeiro dos contratos ${ }^{4}$.

Nessa seara regulatória, aqui optamos discutir algumas questões controversas em relação aos limites da competência regulamentar da ANEEL, partindo da análise do caso da Resolução n. 500/2012, a qual estabelece os procedimentos para reembolso do custo de combustíveis de empreendimento que utilize carvão mineral nacional, por intermédio da Conta de Desenvolvimento Energético - CDE. Essa delimitação da análise se deu tendo em vista que, embora a prolação de tal resolução tenha sido precedida de Audiência Pública, o que possibilitou a participação dos regulados e da sociedade, a decisão é alvo de inconformismo por parte dos agentes regulados afetados diretamente, os quais buscam desconstituí-la, seja por meio de petição ao Ministério de Minas e Energia, seja pela via judicial.

Um dos argumentos utilizado desde a Audiência Pública, levado ao Ministério e também à judicialização, é a (in)competência da Agência de regulamentar a matéria da forma que o fez, estabelecendo eficiência para as usinas à carvão extrapolando os limites impostos pelos standards legais, criando obrigações sem amparo legal (falta de norma primária que autorize). Além disso, o ato normativo em questão estaria em desconformidade com as políticas públicas do setor no que tange a proteção da cadeia produtiva do carvão mineral que, no entendimento dos produtores teria sido gravemente atingida.

\section{DA CONSTITUIÇÃO DA ANEEL: O MODELO REGULATÓRIO BRASILEIRO}

Em 1996, durante a reforma do Estado o governo deu início a implementação do modelo regulatório brasileiro mediante a criação das agências reguladoras como entidades independentes, seguindo o modelo norte-americano da década de 30 (BINENBOJM, 2014, p. 281-282). Esse formato norte-americano era marcado pela propagação do modelo de administração por agência, o que ocorreu de uma forma tão significativa que todas as autoridades públicas daquele País, exceto os três Poderes, são agências (SCHNEIDER, 2013, 
${ }^{4}$ Vide exemplos de diretrizes e políticas públicas nas Leis $\mathrm{n}^{\circ}$ 9.427/1996 e $\mathrm{n}^{\circ}$ 10.848/2004. p. 79). No período em que teve início a regulação por entidades independentes 5 no Brasil, a delegação de função reguladora às agências, assim como a independência ante a ingerência dos Poderes Executivo, Legislativo e Judiciário já haviam sofrido significativa redução nos Estados Unidos.

Como já mencionado, a regulação no Brasil teve início com a criação da agência reguladora do setor elétrico. A Lei no 9.427 de 26 de dezembro de 1996 criou a Agência Reguladora de Energia Elétrica - ANEEL constituída na forma de autarquia especial, pessoa jurídica de direito público, vinculada ao Ministério de Minas e Energia, tendo como finalidade definida no artigo $2^{\circ}$, a regulação e a fiscalização da produção, transmissão, distribuição e comercialização de energia elétrica sempre de acordo com as políticas públicas e diretrizes estipuladas pelo governo federal.

A atuação da Reguladora, seja quando voltada à fiscalização, seja quando relacionada à regulação propriamente dita, se dá em ambiente complexo, que envolve interesses muitas vezes conflitantes de geradoras de energia elétrica, transmissoras, distribuidoras e usuários.

São entidades tidas por "independentes" e especializadas, que contam com corpo técnico altamente capacitado para regular o setor com a competência técnica e no tempo que o contexto social atual exige.

A independência da ANEEL, e das demais agências reguladoras da esfera federal, nada mais é do que uma autonomia reforçada, assegurada por quadro de pessoal próprio, receita própria, diretoria com mandato por prazo determinado e intercalado não sujeita à exoneração ad nutam, o que lhe permite agir dentro dos limites preestabelecidos pela lei e pelas políticas públicas, sem a ingerência direta do Ministério ao qual esteja vinculada ${ }^{6}$, nem mesmo do Presidente da República. Importante ressaltar que essa tentativa de blindagem (BINENBOJM, 2014, p. 287) contra ingerência política e prevalência de uma regulação técnica não pode ser confundida com uma autorização para o agir livre e/ou arbitrário. Aplicam-se às agências, incluindo a ANEEL, todos os princípios que regem a administração pública, notadamente o da legalidade e o dever de motivar seus atos.

Como oportunamente destaca Egon Bockmann Moreira a independência em face do governo e a especialização são meios "para se tentar assegurar a neutralidade regulatória" (MOREIRA, 2006, p. 177). A Agência Nacional de Energia Elétrica - ANEEL foi constituída com acentuado grau de autonomia e corpo técnico especializado para o exercício da atividade

\footnotetext{
$\overline{5}$ Neste trabalho as expressões entidade independente, autarquia especial, agente regulador, agência e reguladora serão utilizadas como equivalentes à agência reguladora independente.

${ }^{6}$ Egon Bockmann Moreira esclarece com propriedade que as agências são vinculadas a determinado Ministério, o que não se confundo com subordinação. São vinculadas, mas não subordinadas. (MOREIRA, 2006, p. 175).
} 
reguladora do setor elétrico que compreende vasto e importante campo de atuação. Neste trabalho o interesse recai de forma particular sobre a competência de regulação propriamente dita, exercida por meio da edição de atos infralegais.

\section{COMPETÊNCIA REGULAMENTAR}

Quando se trata da competência normativa ou regulamentar propriamente dita das agências reguladoras, que consiste na capacidade de editar atos administrativos normativos, diversas são as posições doutrinárias que perpassam desde debates sobre a legalidade até a deslegalização ${ }^{7}$. Luís Roberto Barroso (2002, p. 223) aponta que o cerne do debate acerca do poder normativo das agências reguladoras reside na sua (in)compatibilidade com o princípio da legalidade. Sustenta o autor que é necessário fixar os limites de uma flexibilização legítima. A questão orbita justamente no alcance dos limites normativos das agências quando confrontados com a competência privativa do legislativo.

No entendimento de Marco Juruena Villela Souto (2006, p. 126-128) a regulação tem amparo no art. 174 da Constituição Federal, e adota como premissa o desenvolvimento da atividade regulatória na forma do art. 24, inciso I, também da Constituição Federal, afastando a ideia de que seja uma usurpação da função legislativa, bem como de delegação de poderes, afirmando se tratar de atividade administrativa. Sustenta ainda que a regulação não se confunde com regulamentação atribuída ao Chefe do Poder Executivo, isso porque a atividade de regulação não está limitada à edição de normas, também por ser atividade de ordem técnica e não política e, ainda, por ser voltada à coletividade e não à sociedade como um todo. Assim, a atividade regulamentar não se confunde com a atividade legislativa, devendo limitar-se à estrita observância da lei, bem como dos regulamentos editados pelo Chefe do Executivo.

Nesse sentido, Adriana Maurano (2006, p. 163) afirma que a fixação dos limites de atuação das agências deve pautar-se pelo princípio da legalidade, o qual deve ser interpretado conforme a constituição, tendo o Poder Legislativo a competência geral para legislar, sem excluir a possibilidade de que "outras figuras normativas" venham a completar o sentido da lei. Lais Calil (2006, p. 175), por sua vez, argumenta que a competência destas entidades é estabelecida nas leis que as criam e deve se circunscrever nos limites balizadores dos regulamentos, sujeita a uma escala hierárquica que lhe impõe conformação com as leis, bem como com os regulamentos presidenciais. Em relação à hierarquia das normas, Sérgio Guerra 
${ }^{7}$ Sérgio Guerra conceitua deslegalização como sendo a "retirada de certa matéria do domínio da lei para passa-la ao domínio do regulamento". (GUERRA, 2004, p. 42).

argumenta que não há usurpação de função, nem do legislativo, nem, do Executivo, o que existe é um "poder-dever de exercer uma função normativa secundária" 8 , devendo esta atividade estar em consonância com as normas de hierarquia superior.

Marçal Justen Filho (2002, p. 519) também sustenta a compatibilidade da competência das agências com a previsão do art. 84 da Constituição Federal, entendendo não se tratar de competência privativa do Presidente da República e, portanto, passível de delegação às agências, com a ressalva de que se trata de competência normativa derivada, o que significa "a necessidade de compatibilidade da norma administrativa com a norma legal no tocante a conteúdo, espírito e finalidade", de modo que o espaço discricionário está limitado pela previsão legal (JUSTEN FILHO, 2002, p. 517). Da mesma forma Leila Caéllar (2001, p. 116128) argumenta que a competência das agências é regulamentar considerando não se tratar de competência exclusiva do Poder Executivo. Destaca a importância dos limites impostos a essa atividade regulamentar, o que significa: não inovar de forma absoluta, estar de acordo com a lei e o direito, respeitar o princípio da tipicidade, não restringir liberdade, igualdade e propriedade ou determinar alteração do estado de pessoas e não retroagir.

Sobre a conformidade legal, Egon Bockmann Moreira (2006, p. 185) destaca que as agências provêm normas gerais e abstratas, como "algo que se aproxima do chamado 'regulamento autônomo'. O jurista esclarece que no Brasil não podem existir regulamentos autônomos, por isso refere-se a um regulamento próximo ao autônomo, posto que as agências possuem poder-dever conforme as leis que as instituíram e por essa razão o regulamento deve estar de acordo com a lei, mas ao mesmo tempo não é restrito a um mero regulamento executivo, sendo que age de forma complementar às normas primárias (MOREIRA, 2006, p. 190). Ressalta que o regulamento não pode "criar, de forma inédita e autônoma”, deveres e obrigações sem que haja "lastro normativo" (MOREIRA, 2006, p. 188). Ou seja, a atividade regulamentar só pode atuar a partir de standards estabelecidos em lei. Outro ponto de grande relevância destacado pelo jurista é o dever de fundamentar o regulamento, mediante “motivação pública, de fato e de direito" (MOREIRA, 2006, p. 189).

Em sentido semelhante Tércio Sampaio Ferraz Júnior alega não se tratar de delegação legislativa posto não haver renúncia de competência. Segundo o autor é preciso interpretar o "poder regulamentar como forma de delegação inominada" voltado à implementação e/ou complementação do que o autor chama de leis-quadro, as quais contemplam as diretrizes gerais e os princípios. O Poder Legislativo exerce sua competência por meio de leis fazendo 
${ }^{8} \mathrm{O}$ autor sustenta ser uma função normativa secundária, porque a função primária é competência do Poder Legislativo. (GUERRA, 2004, p. 42-43).

uso de conceitos indeterminados, a partir dos quais a agência dispõe de certa discricionariedade para interpretar, aplicar e editar regulamentação complementar (FERRAZ JÚNIOR, 2006, p. 283).

Diogo de Figueiredo Moreira Neto sustenta que a função normativa destas entidades se enquadra como "deslegalização", como uma espécie de delegação para o exercício de uma atividade técnica afastada da influência das autoridades políticas, limitada a não alterar, nem derrogar leis (MOREIRA NETO, 2007, p. 234). Ainda sobre a deslegalização, no entendimento de Alexandre Santos de Aragão (2013, p. 455), embora os regulamentos não possuam o condão de revogar ou alterar leis, eles servem como instrumento em um processo de revogação de uma lei por outra lei, onde a lei revogadora fixa standards, deixando a regulamentação por conta da agência, que o fará por meio da especialização técnica. Desta forma a deslegalização é subentendida quando a competência regulatória é atribuída por lei e na forma da lei, notadamente no que tange a questões de ordem técnica (especialização) (ARAGÃO, 2013, p. 456). Os atos administrativos regulatórios emitidos pelas agências, na visão do jurista, são "de execução" com amparo no art. 84, IV, da Constituição Federal (ARAGÃO, 2000, p. 288).

O que se observa é que independentemente da classificação e conceituação que cada autor dá para a atividade reguladora propriamente dita, identifica-se um certo consenso entre aqueles que reconhecem a competência de editar atos administrativos normativos no sentido de que o exercício da atividade deve ocorrer na forma e nos limites da lei que o institui. Além da observâncias dos limites legais, também há consenso de que a atividade regulamentar deve observar um espectro amplo, que inclui, como já dito, a lei, mas também os ditames da políticas públicas, bem como outros diplomas legais, os quais fixam standards para o conteúdo regulado.

Assim, podemos afirmar que a atividade de regulação não se confunde com a atividade legislativa, vez que aquela se trata de função administrativa regulamentadora, cujo caráter é complementar, atrelado aos limites e diretrizes pré-definidos em lei (CARVALHO FILHO, 2006, p. 83-84). Esse caráter complementar ressalta a primazia da lei e impõe o controle da legalidade sobre os atos administrativos regulatórios.

As competências da Agência Nacional de Energia Elétrica estão relacionadas no art. $3^{\circ}$ da Lei $n^{\circ} 9.427 / 1996$. Neste trabalho interessa de forma mais pontual a competência definida no inciso I do referido dispositivo, concernente à implementação das políticas públicas e diretrizes fixadas pelo governo voltadas à "exploração da energia elétrica e o aproveitamento dos potenciais hidráulicos, expedindo os atos regulamentares necessários ao cumprimento das 
normas estabelecidas pela Lei $n^{\circ} 9.074$, de 7 de julho de $1995^{\prime \prime} 9$.

Resta evidenciado pela simples leitura do dispositivo supramencionado, como bem apontado por Egon Bokmann Moreira (2006, p. 188), que os atos normativos das agências reguladoras não podem criar obrigações e deveres de forma "inédita e autônoma, sem qualquer lastro normativo". Note-se que, no caso em tela, ao encontro do que o autor sustenta, por meio de standards genéricos a lei outorga, "com precisão", à determinada autoridade, a competência de criar.

Sobre esse espaço regulatório, fixado pelos standards legais, surge uma zona de discricionariedade possível ao órgão regulador. Para alguns doutrinadores, como Marçal Justen Filho (2002, p. 525), ao fazer uso de competência técnica especializada a reguladora exerce atividade discricionária. Isso porque, segundo o autor, existe discricionariedade técnica sempre que a decisão do administrador tiver como fundamento "critérios técnico-científicos".

Um pouco diverso é o entendimento de Maria Sylvia Zanella Di Pietro (2007, p. 12), a qual distingue discricionariedade de discricionariedade técnica. Para a autora, havendo ao menos duas alternativas "válidas perante o direito" será caso de discricionariedade, situação em que deve haver uma escolha fundada em critérios de mérito perante o caso concreto. Quanto à discricionariedade técnica, diz que a análise passa pelos conceitos jurídicos indeterminados. Quando referidos conceitos conduzem a uma única escolha estaremos frente à discricionariedade técnica e quando possibilitarem duas ou mais opções será caso de discricionariedade, desta forma o conceito técnico "não gera discricionariedade porque a solução correta poder ser apontada pela manifestação de órgão técnico, baseada em dados da ciência".

Argumenta, ainda, que para o exercício do poder regulamentar é necessária a possibilidade de escolha de uma solução dentre aquelas que a lei permite. Desta forma,

[...] discricionariedade técnica não constitui verdadeira discricionariedade, não envolve decisão política, porque não dá liberdade de escolha para a Administração. O órgão regulador limita-se a definir um conceito que já está contido na lei e cujo conteúdo vai ser apenas explicitado na norma infra legal. (DI PIETRO, 2007, p. 13).

De outra banda, no entendimento de Lais Calil (2006, p. 176) a discricionariedade técnica é uma discricionariedade reduzida, restrita a escolha do momento da prática do ato, não havendo o que se falar, neste caso, em oportunidade e conveniência.

Por conseguinte, nota-se que os conceitos não residem em paz doutrinária, mas

\footnotetext{
${ }^{9}$ BRASIL. Lei no 9.074/1995. Estabelece normas para outorga e prorrogações das concessões e permissões de serviços públicos e dá outras providências.
} 
apontam a existência de um espaço constituído sobre conceitos indeterminados no qual, sob a égide da legalidade, deve atuar a competência reguladora. Nesse contexto, o espaço regulatório delimitado por standards e políticas públicas atribuídas à regulação por entidade "independente" e tecnicamente especializada acaba por se tornar tema sempre palpitante e, por vezes, motivo de irresignação por parte dos entes regulados, e por outras vezes por parte do próprio governo. Para melhor ilustrar esse tema elegeu-se um ato normativo precedido de audiência pública e alvo de ação judicial para estudo de caso.

\section{ESTUDO DE CASO: A RESOLUÇÃO 500/2012}

Como refletido no item anterior, os limites da competência regulatória das agências repousam sobre conceitos indeterminados que devem ser pautados pelos standards legais e pelas políticas públicas. No entanto, definir o alcance desses conceitos, como já dito, é tarefa árdua e por vezes controversa. No caso aqui analisado, por meio da Resolução Normativa $n^{\circ}$ 500/2012 a ANEEL, entre outras questões, definiu índices de eficiência para as usinas termoelétricas, regulando, com base nesse índice, o percentual de carvão a ser reembolsado pela Conta de Desenvolvimento Energético (CDE). O reembolso do combustível trata-se de incentivo regulamentado pela Lei 10.438/2002, a qual, dentre outras medidas, cria a Conta de Desenvolvimento Energético (CDE), tendo como uma de suas finalidades "o desenvolvimento energético dos Estados e a competitividade da energia produzida a partir do carvão mineral, nas áreas atendidas pelos sistemas interligados, com a duração de 25 anos, i.e, até o ano de $2027^{\prime \prime 10}$.

Por meio do Decreto n. 4.541/2002 foi regulamentada CDE. Na forma do art. 33, inciso I, do referido Decreto, os recursos da CDE poderão ser utilizados "para cobertura dos custos de combustíveis primário e secundário de empreendimentos termelétricos que utilizem apenas carvão mineral nacional, em operação até 6 de fevereiro de 1998”. Na sequência, no art. 34, parágrafo $5^{\circ}$ do mencionado diploma legal consta: "ANEEL poderá ajustar o percentual do reembolso ao gerador, de modo a preservar o atual nível de produção da indústria de carvão e segundo critérios que considerem a rentabilidade do gerador compatível com os riscos minorados que decorrem da Lei n. 10.438, de 2002".

Os procedimentos para reembolso do carvão mineral, a partir de $1^{\circ}$ de janeiro de 2005 , foram regulamentados pela ANEEL por meio da Resolução Normativa nº 129/2004. 
${ }^{10}$ BRASIL, Lei $\mathbf{n}^{\mathbf{o}}$ 10.438/2002. (Art. 13 da redação vigente em 2012, quando foi editada a Resolução Normativa $\mathrm{n}^{\circ} 500$ da ANEEL. A redação atual foi alterada pela Lei $\mathrm{n}^{\circ} 12.783$, de 2013).

Pretendendo alterar referida normativa a agência levou proposta de revisão à Audiência Pública $n^{\circ}$ 043/2011, expondo suas razões por meio da Nota Técnica n. 034/2011SRG/ANEEL, a qual anexou proposta de minuta de resolução alterada. A síntese do conteúdo da Nota Técnica 034/2011-SRG/ANEEL pode ser extraída do seguinte trecho: “[...] propõe-se o estabelecimento de critérios de eficiência energética que estimulem a modernização tecnológica das usinas". Para tanto, a ANEEL, na mesma nota técnica, invocou diretriz prevista no art. 13 da Lei 10.438/2002, “que previu o reembolso de até 100\% do combustível, podendo a ANEEL ajustar o percentual do reembolso ao gerador segundo critérios que considerem sua rentabilidade competitiva e preservem o atual nível de produção da indústria produtora do combustível”.

Essa revisão resultou na edição da Resolução Normativa nº 500/2012, objeto de estudo deste trabalho. Referido ato administrativo normativo foi precedido pela Audiência Pública, $\mathrm{n}^{\circ}$ 043/2011, cujo aviso foi publicado no Diário Oficial da União no 11 de agosto de 2011, informando ter como objetivo

[...]obter contribuições para o aperfeiçoamento da Resolução Normativa $n^{\circ}$ 129/2004 com vistas a estabelecer os procedimentos para reembolso do custo de combustíveis de empreendimento que utilize carvão mineral nacional por intermédio da Conta de Desenvolvimento Energético - CDE.

Constou ainda do aviso a informação de que seriam recebidas contribuições por intercâmbio documental no período compreendido entre o dia 11/8/2011 e o dia 14/10/2011, bem como a previsão de realização de sessão presencial, inicialmente definida para o dia 29 de setembro de 2011 e posteriormente transferida para o dia 30 de setembro de 2011, na sede da Agência. Juntamente com o aviso da Audiência Pública, foi disponibilizado no sítio da ANEEL a já referida Nota Técnica 034/2011 - SRG/ANEEL, bem como minuta da resolução, apresentação técnica da SRG/ANEEL realizada na 29a Reunião Pública Ordinária da Diretoria em 9/8/2011, procedimentos para participação em audiências e consultas públicas e modelo de envio de contribuições.

Na primeira fase da Audiência Pública 43/2011 foram apresentadas 14 contribuições por intercâmbio documental e 20 participações na reunião presencial. Por meio da Nota Técnica $n^{\circ}$ 037/2012-SRG/ANEEL de 29 de maio de 2012, elaborada por especialistas em regulação, foram analisadas as contribuições apresentadas. Além disso, constou na referida 
Nota Técnica proposta de alteração da Resolução Normativa n 129/2004 e a recomendação do acolhimento da proposta e revisão da Resolução nos termos expostos na Nota Técnica.

No início desta Nota consta que o intuito de revisar a Resolução Normativa $n$. 129/2004 é de "incentivar o uso racional e eficiente dos recursos da CDE e a modernização do parque gerador a carvão mineral no Brasil" (ANEEL, 2012, p. 01). Sustentam os especialistas que a Superintendência de Regulação dos Serviços de Geração - SRG “monitora os resultados operativos das centrais termelétricas a carvão mineral, os quais se mostram insatisfatórios do ponto de vista da eficiência energética" (ANEEL, 2012, p. 01), o que acaba por onerar a CDE que subsidia $100 \%$ do mineral consumido. Na sequência a nota expõe o trabalho de monitoramento e fiscalização realizado sobre as termelétricas.

Pontualmente sobre a Audiência Pública n 43/2011, a nota inicia versando que em 31/10/2011 a Superintendência "solicitou parecer da Procuradoria Federal da ANEEL, referente ao questionamento da APINE sobre a atribuição da Agência em regular o benefício da CDE para o carvão mineral" (ANEEL, 2012, p. 02). Na sequência, registra que "pelo Parecer $\mathrm{n}^{\circ} \quad$ 0746/2011/PGE-ANEEL/PGF/AGU (SICnet $\mathrm{n}^{\circ} \quad 47516.015753 / 2011-00$ ) Procuradoria Federal da ANEEL opinou pela competência da Agência, em que pese o argumento do questionamento legal apresentado pela APINE" (ANEEL, 2012, p. 02). Sobre essa questão em particular, importante registrar que o parecer apresentado pela APINE foi disponibilizado no sítio da ANEEL, junto às contribuições apresentadas. O mesmo não ocorreu em relação ao Parecer emitido pela Procuradoria Federal da ANEEL, cujo conteúdo não foi disponibilizado entre os documentos pertinentes a Audiência Pública nº 043/2011.

Passo seguinte, é informado na Nota Técnica 037/2012 que em razão do acolhimento de algumas contribuições apresentadas durante a Audiência Pública foi elaborada nova minuta de Resolução, a qual teria sido disponibilizada no sítio da Agência em 08/03/2015 e estaria disponível até aquela data (29/05/2012). A nota ainda registra que em face da nova minuta de resolução novas contribuições foram apresentadas (ANEEL, 2012, p. 03). Essas novas contribuições não estão disponíveis do sítio eletrônico da ANEEL, motivo pelo qual não serão analisadas nesse trabalho ${ }^{11}$.

Consta ainda, na Nota Técnica (item 15) a informação de que foram apresentadas contribuições das 14 (quatorze) instituições, relacionando-as. Adiante, a nota expressa certa frustração ao evidenciar que havia uma expectativa em relação às contribuições no sentido de que trouxessem informações sobre os custos referentes à geração de energia, bem como sobre a modernização das plantas e condições de mercado relacionadas à venda de energia, 
${ }^{11}$ Em 21/03/2016 entramos em contato com a ANEEL, via consulta telefônica. A agência se comprometeu a verificar porque os arquivos não estão disponíveis, no entanto, até a presente data ainda não foi liberado o acesso.

afirmando que "a maior parte das contribuições colocadas na Audiência Pública não atingiu a sua principal finalidade - apoio ao aperfeiçoamento da norma ora proposta” (ANEEL, 2012, p. 03).

A nota também expõe que a maioria das contribuições se restringiu a "contraposições pontuais aos argumentos e fatos trazidos na Nota Técnica ${ }^{\circ}$ 034/2011-SRG/ANEEL e no pedido de cancelamento da proposta colocada em Audiência Pública" (ANEEL, 2012, p. 04). Relata ainda que os argumentos apresentados para a manutenção da Resolução 129/2004 foram de que a "legislação relacionada ao reembolso do carvão não obriga diretamente os agentes beneficiários a modernizarem suas usinas a carvão" (ANEEL, 2012, p. 04) o que teria sido contraposto pelo Ministério da Fazenda, ao sustentar que a Resolução 129/2004 isenta as usinas beneficiárias do subsídio da lei geral da concorrência.

Apenas algumas das contribuições apresentadas foram analisadas pontualmente e de forma muito sucinta, sendo que somente algumas questões relacionadas a prazos de entrada em vigor e alguns índices sugeridos foram acolhidos. Mantendo-se na essência a proposta inicialmente apresentada no formato da minuta de resolução levada à Audiência Pública. Essa segunda minuta, com as alterações pontuais, também não está disponível no sítio eletrônico da ANEEL junto ao material pertinente a Audiência Pública.

Na Nota Técnica $n^{\circ}$ 037/2012-SRG/ANEEL, os especialistas discorrem sobre a proposta de cálculo do percentual de reembolso em função da eficiência da usina, incluindo a padronização dos procedimentos de medição de consumo do combustível e mecanismos de transparência quanto à gestão do reembolso, apresentando proposta diferente da inicialmente exposta por meio da Nota Técnica 34/2011, a qual estava relacionada ao PLD (Preço de Liquidação da Diferença), passando a ter como base o "reembolso proporcional à eficiência energética da usina em relação a um padrão, com o objetivo de estimular a modernização das usinas" (ANEEL, 2012, p. 07). Proposta esta que foi tecnicamente explicada, incluindo fórmula de cálculo e índices a serem preestabelecidos. Os especialistas também expuseram o resultado da aplicação do reembolso proporcional à eficiência relativamente a cada uma das usinas termelétricas beneficiárias, justificando que "apesar do forte impacto para algumas usinas, o reflexo da redução do gasto de CDE considerando todo o conjunto ficaria em aproximadamente $13,3 \%$, equivalente a $\mathrm{R} \$ 78,6$ milhões do gasto anual de $\mathrm{R} \$ 592$ milhões (ref. 2010)" (ANEEL, 2012, p. 11). 
Pari passu, foram analisadas as contribuições apresentadas por 06 (seis) entidades em face da nova minuta de resolução baseada no reembolso proporcional à eficiência. De igual sorte a análise foi sucinta, limitando-se a questões de prazos para implementações, sendo acolhidas propostas de alterações de alguns prazos. As contribuições, segundo consta na nota, também relataram algumas inconformidades sobre índices de eficiência padrão (faixa de eficiência), de modo que algumas alterações sugeridas também foram acolhidas.

O voto do Diretor Relator basicamente se restringe ao texto da Nota Técnica $n$. 037/2012-SRG/ANEEL, propondo o acolhimento daquilo que foi proposto pelos especialistas, o que, ao final do processo público, foi aprovado pela Diretoria da ANEEL e publicado na forma da Resolução Normativa n. 500/2012. Em apertadíssima síntese, a Resolução 500/2012 definiu as condições gerais para o reembolso dos custos de combustíveis pela CDE, dentre elas o critério de eficiência energética, a necessidade de modernização ou eficientização das centrais geradoras, o sistema de coleta de dados operacionais para a CDE, questões referentes a limites de preços dos combustíveis, entre outras.

Editado o referido normativo, agentes regulados e agentes da cadeia de produção de carvão mineral procuraram o Ministério de Minas e Energia - MME a fim de expor os possíveis efeitos que a regulação dada pela Resolução n. 500/2012 poderia ocasionar a seus negócios. Após reunião com representante da Tractebel Energia e da COPELMI Mineração (entidades beneficiárias do subsídio da CDE). O MME teria recomendado a ambas as entidades que procurassem a ANEEL e propusessem a aplicação do previsto no art. 11 da Lei 9.648/1998, o que acabou sendo indeferido pela Agência Reguladora ${ }^{12}$.

Após esse indeferimento o MEE emitiu a Nota Técnica n. 1/2015-AEREG/SE-MME, na qual relatou que a Tractebel havia sustentado que as máquinas da Usina de Charqueadas, antiga e já no final da vida útil, não poderiam cumprir a meta estipulada pela ANEEL, o que levaria a uma perda de $26 \%$ do reembolso no custo do combustível. Após a negativa da ANEEL as entidades retornaram ao MME, fato que provocou a elaboração da Nota Técnica em questão, na qual é elaborada uma análise com base na legislação que se considerou aplicável ao caso.

A nota conclui que:

(i) na emissão da Resolução Normativa n ${ }^{\circ}$ 500/2012 a ANEEL não considerou "pontos importantes da legislação estabelecida, particularmente o $\S 4^{\circ}$ do art. 13 da Lei $n^{\circ}$ 10.438/2002”, no que tange a "necessidade de preservação do nível de produção das usinas de

\footnotetext{
${ }^{12} \mathrm{O}$ ministério de Minas e Energia sugeriu à COPELMI e à Tractebel Energia procurassem interagir com a ANEEL com vista a aplicar o disposto no art. 11 da Lei no 9.648/98 ao caso, o que representava, em síntese, a
} 
avaliação quanto à possibilidade de extinção da outorga da usina de Charqueadas, e a venda da energia em leilão de energia nova com a continuidade da cobertura do combustível pela CDE, o que foi indeferido pela Reguladora sob o argumento de que a regra em questão se aplica somente às usinas extintas em 1998, ou seja, na época da publicação da Lei. (BRASIL, Ministério de Minas e Energia. Nota Técnica no 1/2015AEREG/SE-MME).

carvão, ou, se o fez, transferiu para o concessionário essa responsabilidade, sem a contrapartida da CDE, o que poderá levar a desativação da UTE, com os consequentes impactos sociais decorrentes";

(ii) ausência de motivação acerca das contribuições apresentadas, especialmente no que diz respeito ao Parecer Jurídico apresentado pela APINE, na audiência pública (contribuição) sobre a (in) competência da ANEEL para regulamentar a matéria;

(iii) utilização de parâmetros de eficiência exigidos pelo inciso VIII do art. $2^{\circ}$ do Decreto 4.541/2002, aplicável às usinas novas sendo que a Resolução 500/2012 se aplica às usinas velhas, que já estão desgastadas e não possuem a mesma tecnologia, sendo que todos os impactos que adviriam desta medida teriam sido alertados por meios das contribuições e participações durante a Audiência Pública 43/2011;

(iv) que não vislumbram impedimento de que extinta uma usina na forma do $\S 2^{\circ}$ do art. 11 da Lei n ${ }^{\circ}$ 9.648/1998 e concedida uma nova, esta continue com o benefício da CDE; e

(v) que a resolução na forma proposta pela ANEEL não deve permanecer, levando a necessidade de construção de alternativas que evitem a desativação das usinas e os impactos que provocariam, sugerindo por fim o encaminhamento da Nota Técnica para avaliação e manifestação da Assessoria Jurídica do Ministério de Minas e Energia .

Registre-se que não dispomos de informações sobre os desdobramentos seguintes, se houveram.

Além da ação junto ao MME pela Tractebel e pela COPELMI, a Companhia de Geração Térmica de Energia Elétrica - CGTEE, protocolou perante a ANEEL, pedido de efeito suspensivo para afastar a aplicação da Resolução Normativa n. 500/2012, sob o argumento principal de que as disposições contidas no referido regulamento inviabilizariam os empreendimentos termelétricos existentes, além de estarem em desacordo com a legislação e com princípios jurídicos, uma vez que, entre outros problemas, a resolução representou inovação a tal ponto que levou à descaracterização da Lei n 10.438/2002. O pedido foi recebido como recurso e autuado no processo 48513.033729/2015-00 em 24/12/2015.

A Associação Brasileira de Geradoras Termelétricas - ABRAGET, na mesma linha insurgente dos agentes acima mencionados, ingressou com ação judicial contra a ANEEL postulando a anulação da Resolução no 500/2012 e a proibição de que a Agência pudesse exigir das geradoras termelétricas "a realização de investimentos em 
modernização/eficientização, como critério para definição do percentual de reembolso do custo de combustível". Postulando ainda, a concessão de liminar (Processo n ${ }^{\circ} 0006217$ 20.2016.4.01.3400-9 $9^{a}$ Vara Federal, TRF $1^{a}$ Região). Nas razões da ação a autora argumenta, em apertada síntese, que por meio da Res. 500/2012 a reguladora extrapolou sua competência, não observando as políticas públicas relacionadas ao desenvolvimento energético e à cadeia de produção do carvão mineral, inovando no ordenamento jurídico ao criar obrigação não prevista em lei. Negada a liminar, o mérito ainda aguarda julgamento.

Pode-se observar a partir da Nota Técnica 37/2012 que as contribuições apresentadas durante a Audiência Pública 43/2011, bem como a Nota Técnica emitida pelo Ministério de Minas e Energia - MME, o recurso interposto pela CGTEE e a petição inicial protocolada pela ABRAGET, lançam de forma recorrente a dúvida sobre a competência da ANEEL para regular a matéria nos termos e na extensão em que o fez. É de se ressaltar ainda que assim como a Nota Técnica emitida pelo Ministério de Minas e Energia - MME, como na petição inicial protocolada pela ABRAGET, é mencionada a falta ou insuficiência de motivação sobre a competência da ANEEL que teria sido sustentado por meio do Parecer n. 0746/2011/PGEANEEL/PGF/AGU.

O tema aparece já na Audiência Pública 43/2011 na qual é apresentado parecer emitido por especialistas em regulação sobre a incompetência da ANEEL, o que levou a Agência a solicitar análise jurídica da Procuradoria Federal, e posterior manutenção da proposta de alteração sob o argumento de que o Parecer emitido teria opinado pela competência, sem maiores justificativas, sem enfrentar pontualmente os argumentos apresentados na contribuição da APINE, na qual foram apresentadas, de forma detalhada, as razões de ordem jurídica pelas quais se vislumbrava a incompetência.

\section{CONSIDERAÇÕES FINAIS}

Em relação à competência regulamentar das agências, embora, como já dito, não haja pleno consenso entre a doutrina, podemos concluir que três principais parâmetros devem ser observados quando do preenchimento prático dos conceitos indeterminados que normatizam a atividade reguladora: respeito aos standards legais, observâncias das políticas públicas e motivação dos atos administrativos exarados. Dito isso, podemos perceber que o cerne do debate está, justamente, nos limites dessa competência, onde a irresignação contra o ato normativo (no caso a Res-500/2012) é sustentada com base em três argumentos que vão ao encontro de nossa conclusões: (i) a agência teria extrapolado os limites e criado obrigações 
sem amparo legal e (ii) a normativa seria contrária às políticas públicas no que tange a proteção da cadeia produtiva do carvão mineral (iii) observou-se precariedade no que tange a motivação do ato administrativo, especialmente no que concerne a refutar as contribuições apresentadas durante a Audiência Pública.

Pois bem, sobre o amparo legal para criar as obrigações advindas da Res-500/2012, como se pode depreender da síntese do processo de audiência pública acima analisado, a ANEEL teria ultrapassado os standards legais ao criar índices de eficiência energética. Esse transbordo de competência pode ser vislumbrado, uma vez que a fixação de tais índices vem a comprometer o desenvolvimento energético e a cadeia de produção do carvão mineral, bem como cria obrigações não previstas em lei, como o caso da aplicação dos parâmetros de eficiência a usinas antigas, sendo que a lei só lhes exige para novos empreendimentos.

Em relação às políticas públicas, por todo arcabouço legal aqui exposto, fica evidente que a política pública de incentivo à cadeia produtiva do carvão mineral orbita como plano de fundo das políticas de incentivo ao desenvolvimento energético, como bem exemplifica a criação da CDE. Quando a ANEEL fixa índices de eficiência que podem, inclusive, inviabilizar negócios, a agência dá de ombros ao incentivo que permeia a normatização do mercado energético e carbonífero, não acolhendo, dessa forma, as diretrizes do executivo.

Além de ser contestada por não acompanhar os standards legais e as políticas públicas, a edição da Res-500/2012 está calcada em decisões que podem ser consideradas arbitrárias, uma vez que é carente de motivação no que diz respeito ao acolhimento ou não das contribuições no processo de audiência pública. A Resolução Normativa $n^{\circ}$ 273/2007/ANEEL, em seu capítulo II, discorre de forma sucinta e precária sobre o procedimento de audiência pública, de modo que na ausência de normativa específica deve ser aplicada a Lei ${ }^{\circ}$ 9.784/1999, que regula o processo administrativo. Esse diploma legal prevê de forma expressa no art. 50, inciso I e II que os atos administrativos que "neguem, limitem ou afetem direitos ou interesses" e/ou "imponham ou agravem deveres, encargos ou sanções" devem ser motivados, devendo constar na motivação a "indicação dos fatos e dos fundamentos jurídicos". Daí podemos inferir que além do mandamento constitucional sobre a motivação dos atos administrativos, no caso da ANEEL, há mandamento específico para que as decisões nos procedimentos de audiências públicas sejam devidamente motivados.

Importante destacar que não se deve confundir motivo com motivação. Enquanto o motivo "é pressuposto de direito que autorizada a edição do ato administrativo", motivação por sua vez "abrange a explicitação dos motivos" (NOHARA, 2009, p. 317-318), por meio do qual deve ser justificado o ato, permitindo aferir, além da ocorrência do motivo, elementos 
como finalidade, moralidade e desvio de poder. O princípio da motivação, positivado no art. $2^{\circ}$ da Lei $n^{\circ} 9.784 / 1999$, assegura que os atos administrativos sejam consonantes com o Estado Democrático de Direito e com o exercício da democracia assegurado na Constituição Federal. É a justificação o meio pelo qual se deve prestar constas à sociedade. A motivação dos atos está diretamente relacionada à concepção de transparência, como meio de assegurar uma gestão pública não autoritária (NOHARA, 2009, p. 318).

Nos processos administrativos regulatórios deve ser promovida de forma efetiva a participação dos interessados, o que inclui a abertura para participação por meio de audiências ou consultas públicas e a publicidade eficiente, mas não se esgota no cumprimento meramente formal destes requisitos. É condição a ser observada que esta participação e esta publicidade sejam eficientes na finalidade de sua realização, o que impõe à agência uma atuação efetiva na promoção da participação. Além disso, não basta que seja promovida a participação dos interessados, é também condicionante a análise das contribuições apresentadas e a devida motivação de sua aceitação ou sua rejeição. Ainda, é fundamental que haja coerência em relação àquilo que foi apurado por meio das contribuições com a decisão da agência, ou seja, o ato administrativo regulamentar deve ser coerente com as contribuições apresentadas durante o processo administrativo que lhe deu origem.

Essa coerência entre a decisão do agente regulador com as contribuições dos agentes regulados e/ou usuários dá legitimidade ao ato. Nessa senda, a decisão só será coerente e legítima se a sociedade for capaz de compreender a forma como suas contribuições foram manejadas. Esse controle só poderá se dar por meio da devida motivação dos atos. A motivação, como já dito, é o instrumento que permite atribuir freios a uma ação arbitrária. Sobre o controle desse possível autoritarismo, ao comentar o princípio de interdicción de la arbitrariedade, previsto na Constituição Espanhola, Tomás Fernandes esclarece a importância da motivação dos atos administrativos como medida de evitar arbitrariedade e viabilizar o controle jurisdicional, assim como o controle social, afirmando que:

\footnotetext{
El concepto de arbitrariedad se vincula así en su esencia última al concepto de motivación, de la que los humanos no podemos prescindir en cuanto entes de razón, ni en el plano del logos, que es y no puede dejar de ser ele del pensamiento (se piensa con palabras), ni, por supuesto, en el plano del Derecho, es decir, del pensamiento y del razonamiento jurídico. El Derecho exige siempre justificación, demanda razones, preserva la razón. Su natureza es la de justifica decisiones, actuaciones. Por eso no puede y no podrá nunca rehuir la cuestión del fundamento (FERNANDES, 1995, p. 164).
}

A emissão de um regulamento é um ato que deve ser motivado, impondo-se a apresentação dos motivos de fato e de direito (CAÉLLAR, 2001, p. 126). A motivação do ato 
administrativo regulatório deve ser técnica ${ }^{13}$. Contudo, a agência reguladora deve fazer de forma que a motivação, muito embora seja técnica, seja compreensível por todos, incluindo aqueles que não dominam a técnica, sob pena de não se prestar ao fim que se lhe impõe, que é de permitir o controle pela sociedade, bem como o jurisdicional e o legislativo. A falta ou insuficiência de motivação é razão suficiente para a anulação do ato. Como bem assinala Ricardo Duarte Júnior (2014, p. 205), a legitimidade do ato normativo encontra-se não apenas no resultado, é aferida, também, no nível de democratização do procedimento que levou à decisão. Essa democratização tem como paradigma “argumentação, diálogo, motivação e racionalidade” (DUARTE JÚNIOR, 2014, p. 205), definidos como fundamentais na obtenção de resultados mais céleres, mais justos e menos onerosos.

No caso em exame, da análise dos documentos disponibilizados pela ANEEL, pode-se depreender que não há muita coerência entre as contribuições apresentadas nas audiências públicas durante o processo administrativo com a decisão final da Agência, tampouco se observa decisão adequadamente motivada, que analise pontualmente todos os argumentos apresentados por meio das contribuições colhidas durante as Audiência Pública, vez que de modo geral foram refutadas sem que fossem explicitadas as razões para tanto. Por conseguinte, o que se pode aferir é que a Res-500/2012 parece não ter respeitado os limites da competência regulamentar, tanto no que tange o respeito aos standards legais e às políticas públicas que regem essa competência, bem como ao que diz respeito à necessária motivação dos atos administrativos no processo de audiência pública. 


\section{REFERÊNCIAS BIBLIOGRÁFICAS}

AGUILLAR, Fernando Herren. O Controle Social de Serviços Públicos. São Paulo: Max Limonad, 1999.

ARAGÃO, Alexandre Santos de. Agências Reguladoras e a Evolução do Direito Administrativo Econômico. 3. ed. Rio de Janeiro: Forense, 2013.

ARAGÃO, Alexandre Santos de Aragão. O Poder Normativo das Agências Reguladoras Independentes e o Estado Democrático de Direito. Revista de Informação Legislativa. Brasília a.37 n. 148 out./dez. 2000.

BARROSO, Luís Roberto. Agências Reguladoras. Constituição, transformações do

\footnotetext{
${ }^{13}$ Marcos Juruena Villela Souto sustenta que o princípio da motivação impõe que a o ato regulatório seja motivado levando em consideração as contribuições da sociedade. Essa motivação na concepção do autor deve ser técnica por tratar-se de uma peculiaridade da regulação a qual requer conhecimento especializado por daquele que regula - "princípio da especialidade"(2006, p. 131).
}

Estado e legitimidade democrática. Revista de Direito da Procuradoria Geral, Rio de Janeiro, n.56, 2002.

BINENBOJM, Gustavo. Uma teoria do direito administrativo: direitos fundamentais, democracia e constitucionalização. Rio de Janeiro: Renovar, 2014.

BRASIL, Agência Nacional de Energia Elétrica - ANEEL. Nota Técnica 034/2011SRG/ANEEL, de 15/06/2011. Disponível em:

<http://www2.aneel.gov.br/aplicacoes/audiencia/arquivo/2011/043/documento/nota_tecni ca_034_2011_srg.pdf >. Acesso em 03 mar. 2016.

BRASIL, Agência Nacional de Energia Elétrica - ANEEL. Nota Técnica no 037/2012SRG/ANEEL, de 29 de maio de 2012. Disponível em:

<http://www.aneel.gov.br/audiencias-publicas>. Acesso em 04 abr. 2016.

BRASIL. Agência Nacional de Energia Elétrica - ANEEL. Resolução Normativa n.500/2012. Disponível em: 〈http://www2.aneel.gov.br/cedoc/ren2012500.pdf >. Acesso em: 25 mar. 2016.

BRASIL. Câmara dos Deputados. Exposição de motivos no 11 do Ministério de Minas e Energia - MME. Diário da Câmara dos Deputados. Brasília, 1996.

BRASIL, Ministério de Minas e Energia. Nota Técnica nº 1/2015-AEREG/SE-MME. 
BRASIL. Lei $\mathbf{n}^{\mathbf{0}}$ 9.074/1995. Estabelece normas para outorga e prorrogações das concessões e permissões de serviços públicos e dá outras providências.

BRASIL, Lei $\mathbf{n}^{\mathbf{0}} \mathbf{1 0 . 4 3 8 / 2 0 0 2}$. Cria o Programa de Incentivo às Fontes Alternativas de Energia Elétrica (Proinfa), a Conta de Desenvolvimento Energético (CDE), dentre outras disposições.

CAÉLlAR, Leila. As Agências Reguladoras e seu Poder Normativo. São Paulo: Dialética, 2001.

CALIL, Laís. O Poder Normativo das Agências Reguladoras em face dos Princípios da Legalidade e da Separação do Poderes. In BINENBOJM, Gustavo (Coord.). As Agências Reguladoras e Democracia. Rio de Janeiro: Lumen Juris, 2006.

CARVALHO FILHO, José dos Santos. Agências Reguladoras e Poder Normativo. In ARAGÃO, Alexandre Santos de (Coord.). O Poder Normativo das Agências Reguladoras. Rio de Janeiro: Forense, 2006.

CARDOSO, Henrique Ribeiro. Controle da Legitimidade da Atividade Normativa das agências Reguladoras. Rio de Janeiro: Lumen Juris, 2010.

DI PIETRO, Maria Sylvia Zanella. Discricionariedade Técnica e Discricionariedade Administrativa. Revista Eletrônica de Direito Administrativo Econômico, no ${ }^{\circ}$, Salvador, fev./mar./abr. 2007, p. 12. Disponível em <http://www.direitodoestado.com/revista/REDAE9-FEVEREIRO-2007-MARIA\%20SYLVIA.pdf>. Acesso em: 28 jan. 2016.

DUARTE JÚNIOR. Ricardo. Agências Reguladoras, Poder Normativo e

Democracia Participativa: uma questão de legitimidade. Curitiba: Juruá, 2014.

FERNANDES, R. Tomás. De la Arbitrariedad de la Administración. $2^{\text {a }}$ ed. Madrid: Civitas, 1995.

FERRAZ JÚNIOR, Tércio Sampaio. O Poder Normativo das Agências Reguladoras à Luz do Princípio da Eficiência. In ARAGÃO, Alexandre Santos de (Coord.). O Poder Normativo das Agências Reguladoras. Rio de Janeiro: Forense, 2006.

GUERRA, Sérgio. Introdução ao Direito das Agências Reguladoras. Rio de Janeiro: Freitas Bastos, 2004.

JUSTEN Filho, Marçal. O Direito das Agências Reguladoras Independentes. São Paulo:

Dialética, 2002.

MOREIRA, Egon Bockmann . Os limites à Competência Normativa das Agências Reguladoras in ARAGÃO, Alexandre Santos de (Coord.). O Poder Normativo das Agências Reguladoras. Rio de Janeiro: Forense, 2006.

MOREIRA NETO. Diogo de Figueiredo. Mutações do Direito Administrativo. $13^{\mathrm{a}}$ ed. Rio de Janeiro: Renovar, 2007. 
MOURANO, Adriana. A Função Normativa das Agências Reguladoras no Brasil e o Princípio da Legalidade. São Paulo: Scortecci, 2006.

NOHARA, Irene Patrícia; MARRARA, Thiago. Processo Administrativo: Lei ${ }^{\circ}$ 9.784/99

comentada. São Paulo: Atlas, 2009.

SCHNEIDER, Yuri. Agências reguladoras e democracia: a necessária aplicação do modelo de democracia cooperativa reflexiva do conhecimento para legitimação de sua atuação. 2013. Tese (Doutorado em Direito) - Programa de Pós-Graduação em Direito, Universidade do Vale do Rio dos Sinos, São Leopoldo, 2013.

SOUTO, Marco Juruena Villela. Extensão do Poder Normativo das Agências Reguladoras. In ARAGÃO, Alexandre Santos de (Coord.). O Poder Normativo das Agências Reguladoras. Rio de Janeiro: Forense, 2006. 